\title{
How Do Uterine Leiomyomas affect the course of Pregnancy and Labor-A Prospective Study
}

\author{
Authors \\ Dr Anjan Dasgupta ${ }^{1}$, Sanghamitra Dasgupta ${ }^{2 *}$ \\ ${ }^{1}$ Associate Professor, Dept. of G\&O, Midnapore Medical College, West Bengal \\ ${ }^{2}$ Msc Nursing, Senior Sister Tutor, RGK Medical College, West Bengal \\ *Corresponding Author \\ Sanghamitra Dasgupta \\ Msc Nursing, Senior Sister Tutor, RGK Medical College, West Bengal, India
}

\begin{abstract}
Prevalence of uterine leiomyoma among pregnant women is approximately $2 \%$ and more common in primipara. Leiomyoma with pregnancies are always at high risk as it may be associated with a number of complications like abortion, preterm labor, premature rupture of membranes (PROM), malpresentation, low lying placenta, intrauterine growth restriction (IUGR) and many others. During labor, dystocia, operative interferences like LUCS and post partum hemorrhage (PPH) are often encountered.

Objective: To evaluate the effects of leiomyoma on the course of pregnancy, labor and mode of delivery.

Materials and Method: The study was a prospective and observational study and carried out in a tertiary care hospital of city Kolkata, West Bengal with ethical approval. The study population included the antenatal mothers who attended antenatal OPD from the first trimester of pregnancy. A total of 102 mothers were taken in the study group as case-control study. Group L $(n=51)$, consist of the pregnant mothers having USG confirmed leiomyoma with pregnancy, considered as case. Leiomyoma size of at least $3 \mathrm{~cm}$ in diameter was included in the study. Group C $(n=51)$ was the pregnant mothers relatively matched with age, parity and gestational weeks with group L, but without having uterine leiomyoma, served as control.

Results: Major portion of pregnant mothers with leiomyoma belonged to nulliparous group. There was higher percentage of termination of pregnancy before 28 weeks ( $p<0.05)$, preterm labor $(p<0.05)$, LUCS $(p<0.05)$, PPH $(p<0.05)$, low birth weight baby $(p<0.05)$ and lower percentage of vaginal delivery $(p<0.05)$ among pregnancy with leiomyoma group (Group- L) compared to pregnancy without leiomyoma group (Group-C).

Conclusion: Uterine leiomyoma may adversely affect the course of pregnancy, labor and mode of delivery.

Keywords: Leiomyoma, Preterm labor, PROM, Malpresentation, IUGR, LUCS, PPH.
\end{abstract}

\section{Introduction}

Uterine leiomyoma, also known as myoma or fibroid, is a common benign smooth muscle tumors of the uterus; occurs in the reproductive age group and its incidence during pregnancy is approximately $2 \% \%^{1,2}$. It has the potential to enlarge during pregnancy as well as to regress after menopause. Leiomyomas vary in their location; may develop as submucous, subserosal or intramural growths and likely caused by estrogen stimulation. The stimulatory effects of pregnancy on myoma growth are unpredictable and may responds differently in individual woman, thus may grow, regress or remain 
unchanged in size during pregnancy ${ }^{3,4}$. Pregnancies with uterine myoma are always at high risk as they are frequently associated with abortion, preterm labor, PROM (premature rupture of membrane), placental abruption, fetal malpresentation, obstructed labor, caesarian delivery and post partum hemorrhage ${ }^{1,5,6}$.The two most important factors which determines morbidity in pregnancy are leiomyoma size and its location $^{7}$. The proximity of myomas to the placental site is also a factor, especially abortion, preterm labor, placental abruption and post partum hemorrhage; all are increased if the placenta is adjacent to or implanted over a leiomyoma. On the other hand, tumor in the cervix or lower uterine segment may obstruct labor. Malpresentations, especially breech presentations are reported to be high and the size and location of leiomyoma might predict the magnitude of the risk $^{8}$. Women with uterine leiomyomas were at higher risk for poor birth outcomes like low birth weight and congenital malformations than women having without leiomyoma ${ }^{9}$.

\section{Materials and Methods}

The aim of the study was to evaluate the effects of leiomyoma on the course of pregnancy, complications during pregnancy and labor and mode of delivery. The study was prospective and observational in nature. It was carried out in a tertiary care hospital of city Kolkata, West Bengal in the department of Obstetrics and Gynecology for one year with ethical approval. The study population included the antenatal mothers who attended antenatal OPD from the first trimester of pregnancy. A total of 102 mothers were taken in the study group as case-control study. Group L $(\mathrm{n}=51)$, was the pregnant mothers having USG confirmed leiomyoma with pregnancy, considered as case. Leiomyoma size of at least $3 \mathrm{~cm}$ in diameter was included in the study. Group C $(\mathrm{n}=51)$ was the pregnant mothers relatively matched with age, parity and gestational weeks with group L, but without having uterine leiomyoma, served as control. All mothers under selection were counseled about abnormal signs and symptoms and advised to attend clinic or emergency even earlier if there were such symptoms. The purpose interrogation and investigations were explained to every mother and written informed consent was obtained from each woman in her own language.

Proper history taking, physical and obstetrical examination done in each case. Obstetrical examination included measurement of fundal height, different obstetrical grips to detect presentation and position of fetus, fetal heart auscultation and pelvic examination where necessary. During active phase of labor, meticulous obstetrical and internal examination was done in each case to rule out cephalo pelvic disproportion and planning for mode of delivery.

Inclusion criteria included pregnant women who attended the antenatal OPD or emergency with sonographically identified uterine leiomyoma was considered as case. Pregnancy without leiomyoma matched with age, parity and gestational weeks served as control. Exclusion criteria included pregnant women with less than $3 \mathrm{~cm}$ sized leiomyoma, pregnancy with uncertain gestational age, multiple gestations with or without leiomyoma and pregnancy with fibroid with previous caesarean section.

All the essential hematological and biochemical investigations were done in the Hematology and Biochemistry department of the institution and ultrasonography at the department of Radiology. For each case and control subject, ultrasonography was done routinely in different trimesters of pregnancy to observe feto-placental profile along with number, size and location of leiomyomas where present. All other data collected from Labor Room Record Book, Antenatal Record Book, OT Registrar and Bed Head Ticket.

After completion of the study, primary data were collected and a master chart prepared. Data entered and analyzed with the help of Microsoft Excel and Epi info (5) software. Probability outcomes of two different groups were expressed in terms of odds ratio (OR) and relative ratio 
(RR). Qualitative data were expressed in terms of number, percentage and chi-square test. In all proportions, $\mathrm{p}$ value $<0.05$ will be considered as statistically significant.

\section{Results and Analysis}

After satisfying all inclusion and exclusion criteria, a total of 102 pregnant mothers were selected under study. 51 pregnant mothers with uterine leiomyoma were included as Case (GroupL) and 51 pregnant mothers without leiomyoma were included as Control (Group-C). Both groups were relatively matched with age, parity and gestational weeks.

Table-1 Distribution of study group according to age

\begin{tabular}{|l|c|c|c|c|}
\hline \multirow{2}{*}{ Age in years } & \multicolumn{2}{|c|}{ Group L $(\mathrm{n}=51)$} & \multicolumn{2}{c|}{ Group C (n=51) } \\
\cline { 2 - 5 } & Number & Percentage & Number & Percentage \\
\hline Up to 19 & 1 & 1.97 & 1 & 1.97 \\
\hline $20-25$ & 8 & 15.68 & 8 & 15.68 \\
\hline $26-30$ & 32 & 62.74 & 33 & 64.70 \\
\hline $31-35$ & 7 & 13.73 & 7 & 13.73 \\
\hline$>35$ & 3 & 5.88 & 2 & 3.92 \\
\hline Total & 51 & 100.00 & 51 & 100.00 \\
\hline
\end{tabular}

The table shows that major portion of pregnant mothers with leiomyoma belonged to 26-30 years age group i.e. $62.74 \%$.
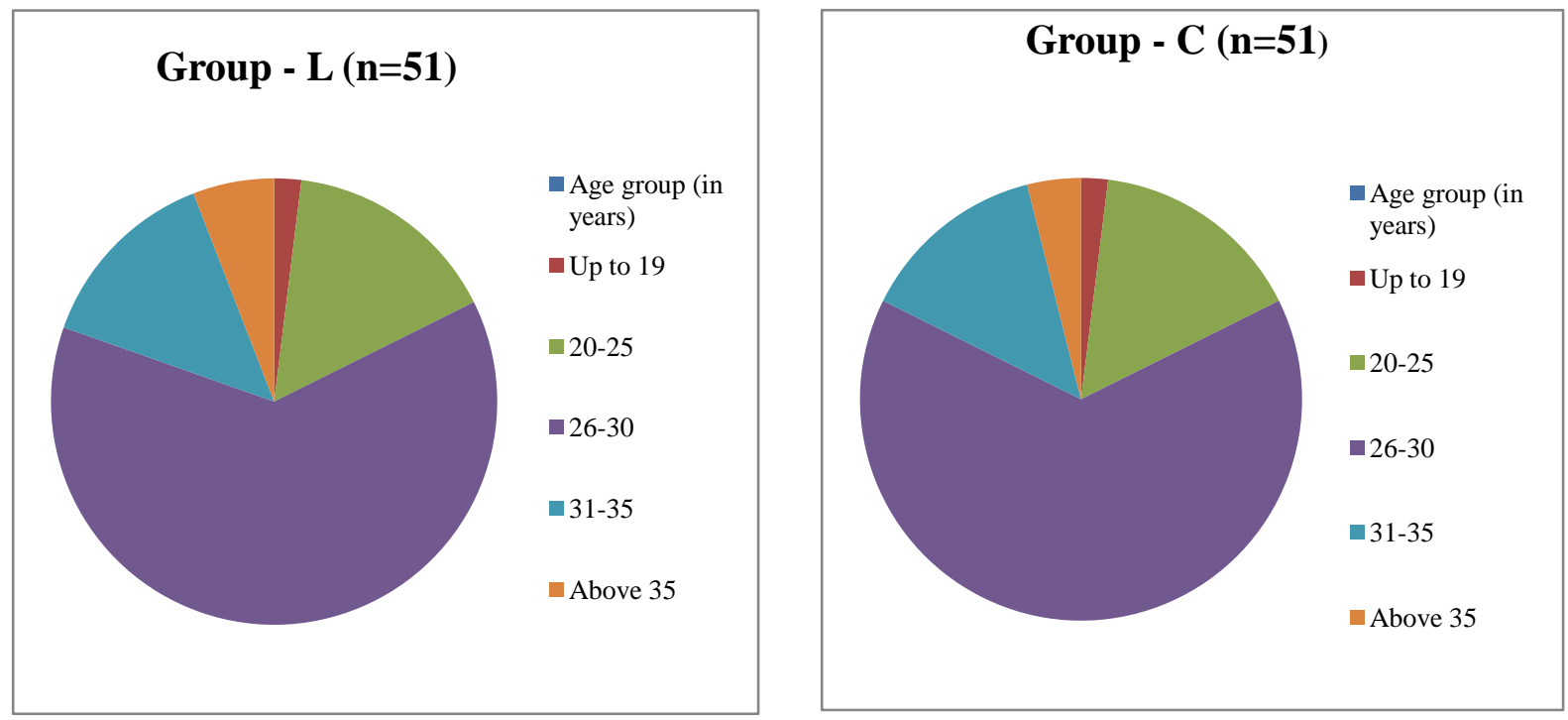

Figure-1 Showing the age wise distribution of study group

Table-2 showing distribution of study group according to parity

\begin{tabular}{|l|c|c|c|c|}
\hline \multirow{2}{*}{ Parity } & \multicolumn{2}{|c|}{ Group L $(\mathrm{n}=51)$} & \multicolumn{2}{c|}{ Group C $(\mathrm{n}=51)$} \\
\cline { 2 - 5 } & Number & Percentage & Number & Percentage \\
\hline Nullipara & 35 & 68.62 & 36 & 70.58 \\
\hline Multipara & 16 & 31.38 & 15 & 29.42 \\
\hline Total & 51 & 100.00 & 51 & 100.00 \\
\hline
\end{tabular}

$\mathrm{X}^{2}=0.05 ; \mathrm{P}=0.8296 ; \mathrm{OR}=0.91 ; \mathrm{RR}=0.96 ;$ Non significant.

The table shows that majority of pregnant mothers with leiomyoma belonged to nullipara group, 35 cases $(68.62 \%)$ out of 51 and it was found only 16 cases $(31.38 \%)$ of multipara. As control group was relatively matched with parity, it was statistically insignificant. 


\section{Figure 2}
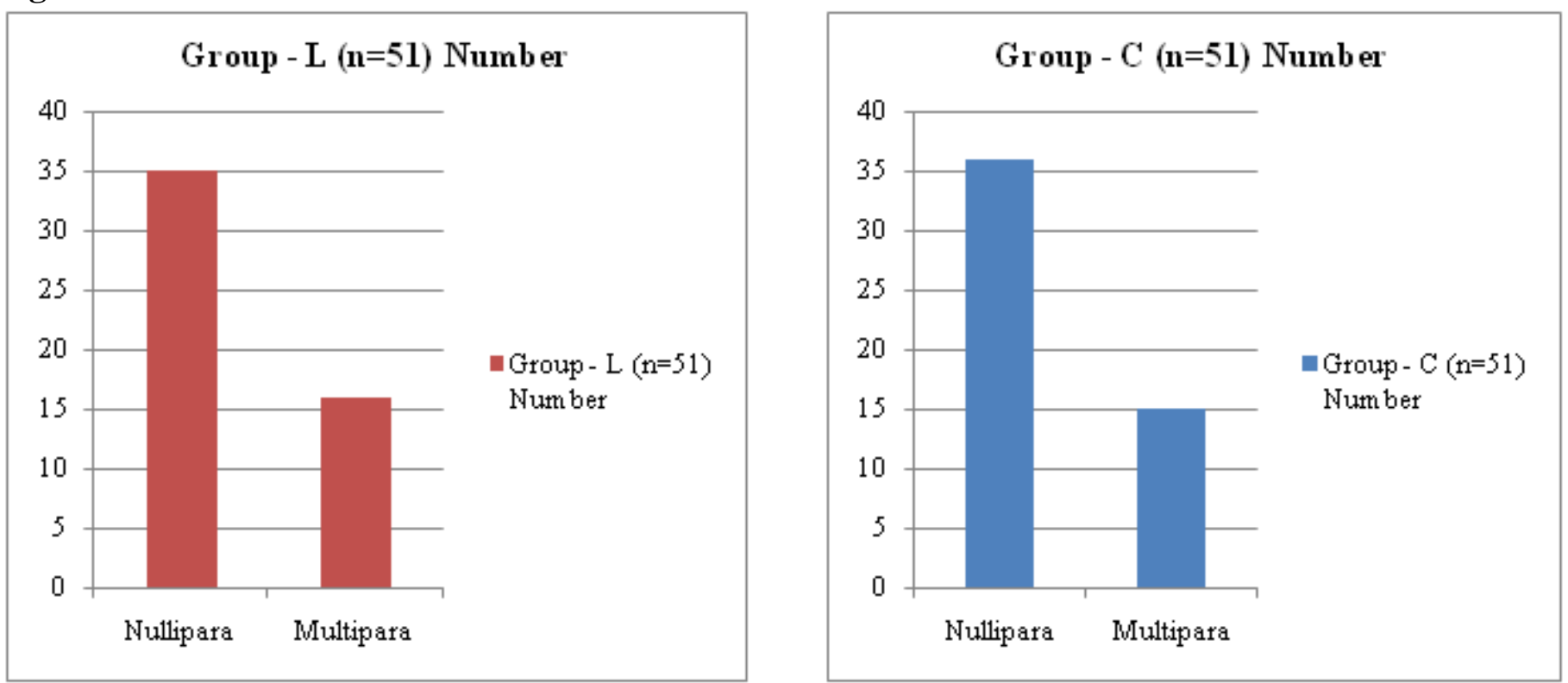

Figure2 showing parity wise distribution of study group

Table -3 Distribution of study group according to gestational age.

\begin{tabular}{|l|c|c|c|c|}
\hline $\begin{array}{l}\text { Gestational age } \\
\text { (week) }\end{array}$ & \multicolumn{2}{|c|}{ Group L (n=51) } & \multicolumn{2}{c|}{ Group C (n=51) } \\
\hline & Number & Percentage & Number & Percentage \\
\hline Up to 28 & 8 & 15.69 & 4 & 7.84 \\
\hline $29-<37$ & 15 & 29.41 & 5 & 9.80 \\
\hline $37+$ & 28 & 54.90 & 42 & 82.36 \\
\hline Total & 51 & 100.00 & 51 & 100.00 \\
\hline
\end{tabular}

$X^{2}=9.13 ; \quad P=0.01 ; \quad \mathrm{df}=2 ; \quad$ Significant

The above table shows that $15.69 \%$ of pregnancy with leiomyoma had terminated before 28 weeks of gestation compared to only $7.84 \%$ in pregnancy without leiomyoma. So, pregnancy termination before 28 weeks of gestation is pretty high in Lgroup than the $\mathrm{C}$ - group. Again, termination of pregnancy in between 29-<37 completed weeks of gestation in pregnancy with leiomyoma is $29.41 \%$ compared to $9.80 \%$ in control. Moreover, termination after 37 completed weeks in pregnancy with leiomyoma group was $54.90 \%$ compared to $82.36 \%$ in pregnancy without leiomyoma group. So there was more percentage of preterm pregnancy and less percentage of term pregnancy in pregnancy with leiomyoma group than the control group and it is statistically significant $(P<0.05)$.

Table 4: Comparison of different parameters between two groups

\begin{tabular}{|l|c|c|c|c|c|c|}
\hline \multirow{2}{*}{ Parameters } & \multicolumn{2}{|c|}{ Group $-\mathrm{L}(\mathrm{n}=51)$} & \multicolumn{2}{c|}{ Group $-\mathrm{C}(\mathrm{n}=51)$} & \multirow{2}{*}{$P$ value } & Inference \\
\cline { 2 - 6 } & Number & Percentage & Number & Percentage & & \\
\hline Abortion & 8 & 15.68 & 4 & 7.84 & 0.218 & Insignificant \\
\hline Preterm labor & 15 & 29.41 & 5 & 9.80 & 0.013 & Significant \\
\hline PROM & 12 & 23.52 & 8 & 15.68 & 0.318 & Insignificant \\
\hline Malpresentation & 11 & 21.56 & 5 & 9.80 & 0.10 & Insignificant \\
\hline LSCS & 31 & 60.78 & 13 & 25.49 & 0.000 & Significant \\
\hline Vaginal delivery & 12 & 23.52 & 34 & 66.66 & 0.000 & Significant \\
\hline PPH & 8 & 15.68 & 2 & 3.92 & 0.046 & Significant \\
\hline
\end{tabular}

$\left(X^{2}=1.51 ; \quad P=0.218 ; \quad \mathrm{OR}=2.19 ; \quad \mathrm{RR}=1.40\right)$

The table shows that, though there was $15.68 \%$ abortion rate in the $\mathrm{L}$ group compared to $7.84 \%$ in the $\mathrm{C}$ group, it was statistically not significant The table also shows that the percentage of preterm labor ( $<37$ completed weeks) in pregnant 
women with leiomyoma (Group L) was $29.41 \%$, whereas it was only $9.80 \%$ in pregnancy without leiomyoma (Group C). $\mathrm{P}$ value is significant $(\mathrm{P}<0.05)$, so preterm labor was higher in Group $\mathrm{L}$ $\left(X^{2}=6.22 ; \quad P=0.013 ; \quad\right.$ df $=1 ; \quad \mathrm{OR}=3.83 ; \mathrm{RR}=$ 1.71). Though the above table shows that the percentage of PROM was in Group L (23.52\%) was higher compared to Group C (15.68\%), it was statistically not significant $\left(X^{2}=1.00 ; \quad P=0.318\right.$; df $=1 ; \quad$ OR $=1.65 ; \quad$ RR +1.26). Similarly, the incidence of malpresentations was more common in Group L than Group C, more than double, but it was statistically not significant $\left(X^{2}=2.67\right.$; $P=0.10 ; \quad \mathrm{OR}=2.53 ; \quad \mathrm{RR}=1.48)$. From the above table, it has seen that the rate of LSCS was much higher, more than double in Group $\mathrm{L}$ (60.78\%) compared to Group C (25.49\%). So LSCS rate was much higher in pregnant mother with leiomyoma and statistically highly significant $(P<0.05)\left(X^{2}=12.95 ; \quad P=0.0003 ; \quad \mathrm{df}=1 ; \quad\right.$ OR $=4.53 ; \mathrm{RR}=2.04)$. Above table also shows that vaginal delivery rate was much lower in pregnancy with leiomyoma group $(23.52 \%$, Group -L) than pregnancy without leiomyoma group (66.66\%, Group-C) and again it was statistically highly significant $\left(P<0.05 \quad\left(X^{2}=19.16 ; P=\right.\right.$ $0.0001 ; \quad \mathrm{df}=1 ; \quad \mathrm{OR}=0.15 ; \quad \mathrm{RR}=0.37)$. The table clearly shows that the incidence of PPH was more in pregnancy with leiomyoma $(15.68 \%$, Group-L) than pregnancy without leiomyoma (3.92\%, Group-C) and statistically significant $(P$ <0.05) $\left(X^{2}=3.99 ; \quad P=0.046 ; \quad\right.$ OR $=4.56$; $\mathrm{RR}=1.71)$.

Table 5 Birth weight of the Babies among two groups.

\begin{tabular}{|l|c|c|c|c|}
\hline $\begin{array}{l}\text { Birth } \\
\text { weight(gm) }\end{array}$ & \multicolumn{2}{|c|}{ Group L } & \multicolumn{2}{c|}{ Group C } \\
\hline & Number & Percentage & Number & Percentage \\
\hline$<2500$ & 15 & $29.41 \%$ & 8 & $15.68 \%$ \\
\hline$>/=2500$ & 28 & $54.90 \%$ & 39 & $76.47 \%$ \\
\hline
\end{tabular}

$X^{2}=3.77 ; \quad P=0.052 ; \quad \mathrm{df}=1 ; \quad$ OR $=2.61 ; \quad \mathrm{RR}=1.56 ;$ Significant.

From the above table, it has seen that the incidence of low birth weight (LBW, <2500gm) baby was more in Group L $(29.41 \%)$ than Group
C (15.68\%). Similarly, birth weight more than $2500 \mathrm{gm}$ was $54.90 \%$ in Group L, which was much lower than Group C (76.47\%).So there is increased chance of having LBW baby in pregnancy with leiomyoma as the result is statistically significant $(P<0.05)$.

\section{Discussion}

Leiomyoma is the most common benign uterine neoplasm in the reproductive age group. The prevalence of leiomyoma during pregnancy is likely to be increase as more women delay child bearing until later in life. It is more common in primipara than of multipara ${ }^{10}$. Complications including pregnancy loss can occur with leiomyoma although most patients have uncomplicated pregnancy and delivery. One study ${ }^{11}$ mentioned $10 \%$ rate of pregnancy complications in leiomyoma uterus and the risk of complication is influenced by both myoma size and its location ${ }^{12}$.

Table 1 shows that $62.74 \%$ (32/51) of pregnant women with leiomyoma belonged to 26-30 years age group. More broadly, 76.47\% (39/51) belonged to 26-35 years age group and only $1.96 \%$ was under 20 years. So major portions of pregnancy with leiomyoma were of 26-35 years in this study, whereas the study by Gloria et $\mathrm{al}^{9}$ showed about $59 \%$ of cases belonged to 25-34 years age group and below 25 years age group was only $4.1 \%$.

Table 2 shows that $68.62 \%$ (35/51) of pregnancy with leiomyoma belonged to nulliparous group and $31.38 \%(16 / 51)$ belonged to multiparous group. By the way, study by G Iram Qidwai et al ${ }^{13}$ found $57.4 \%$ of nulliparous and $42.6 \%$ of multiparous women in pregnancy with leiomyoma in their study. Another study by Gloria et $\mathrm{al}^{9}$ showed nullipara with leiomyoma in $57.7 \%$ and multipara in $15.6 \%$ of cases. So these inferences indicate that the incidence of pregnancy with leiomyoma is high in nullipara.

Table 3 shows that termination of pregnancy less than or equal to 28 weeks in Group L was $15.68 \%$ $(8 / 51)$ compared to $7.84 \%(4 / 51)$ in Group C. 
Premature termination, i.e. between $29-<37^{\text {th }}$ completed weeks of gestation in Group L was $29.41 \%(15 / 51)$ whereas in Group C, it was only $9.80 \%(5 / 51)$. Pregnancy termination after $37^{\text {th }}$ completed weeks was $54.90 \%$ (28/51)in Group L compared to $82.36 \%(42 / 51)$ in Group C. All these results in our study suggested that premature termination was more frequent in pregnancy with leiomyoma than without leiomyoma group and was statistically significant $(\mathrm{p}<0.05)$.

Table 4 shows comparison of different parameters between Group L (pregnancy with leiomyoma) and Group C (pregnancy without leiomyoma). The rate of abortion in Group L was $15.68 \%$ (8/51) compared to $7.84 \%(4 / 51)$ in Group C. Though the rate of pregnancy loss in Group L increased twice the rate of Group C, it was statistically not significant, probably due to small sample size. A study by Benson $\mathrm{CB}$ et $\mathrm{al}^{14}$ showed the rate of spontaneous pregnancy loss in women with fibroid almost twice the rate in women with normal uterus. Vollenheven et $\mathrm{al}^{15}$ also observed high rate of miscarriage in pregnancy with submucous fibroid in their study.

Again, the Table 4 shows $29.41 \%$ (15/51) preterm labor in Group L compared to $9.80 \%(5 / 51)$ in Group $\mathrm{C}$ and it was statistically significant $(\mathrm{p}<0.05)$. So preterm labor was high in pregnancy with leiomyoma group in our study. Similar results of increased preterm labor in pregnancy with leiomyoma had observed by Shailesh Kore et $\mathrm{al}^{16}$ and G Iram Qidwai et $\mathrm{al}^{13}$ in their studies.

Leiomyoma, particularly of submucous variety may be associated with increased incidence PROM. The probable causes include increased friability of membranes, high rate of infection and increased association of preterm birth. Though the incidence of PROM was high in Group L (23.52\%) compared to Group C (16.68\%), there was insignificant association $(\mathrm{p}>0.05)$ between the two groups. However, the study done by G Iram Qidwai ${ }^{13}$ found increased incidence of PROM and Gloria et $\mathrm{al}^{9}$ found insignificant association of PROM in their studies.
In our study, caesarean section in Group L was $60.78 \%(31 / 51)$ in compared to $25.49 \%(13 / 51)$ in Group C (Table 4). The common indications for LUCS were fibroid in lower segment, cervical fibroid, malpresentation, PROM, mechanical obstruction, placenta praevia and inco-ordinated uterine contractions. The higher rate of LUCS was also statistically significant $(\mathrm{p}<0.05)$. Similar higher rate of caesarean section in pregnancy with leiomyoma also observed in their studies done by Katz et $\mathrm{al}^{17}$ and Gloria D et $\mathrm{al}^{9}$.

In our study, vaginal birth in Group L was $23.52 \%$ $(12 / 51)$ whereas in Group C, it was $66.66 \%$ $(34 / 51)$. So the incidence of vaginal birth was less among pregnancy with leiomyoma group compared to pregnancy without leiomyoma group. $\mathrm{P}$ value was highly significant $(\mathrm{p}<0.05)$ (Table4).

The rate of $\mathrm{PPH}$ in pregnancy with leiomyoma group was high in our study than that of pregnancy without leiomyoma group. Table 4 showed $15.68 \%$ (8/51) PPH in Group L compared to only $3.92 \%(2 / 51)$ in Group C with significant $\mathrm{p}$ value $(\mathrm{p}<0.05)$. The main causes of PPH were uterine atony, genital tract injury due to increased operative procedure, retained placental tissue and few cases of placenta praevia. G Iram Qidwai et $\mathrm{al}^{13}$ also found increased incidences of $\mathrm{PPH}$ $(8.3 \%)$ in leiomyoma group compared to without leiomyoma group $(2.9 \%)$ with significant $p$ value. Regarding birth weight of babies, Table 5 showed LBW (<2500gm) was $29.41 \%$ (15/51)in Group L compared to $15.68 \%(8 / 51)$ in Group C. On the other hand, birth weight $=/>2500 \mathrm{gm}$ in Group L was $54.90 \%$ (28/51), whereas in Group C it was $76.47 \%$ (39/51).So in our study, there was significant association between LBW baby and pregnancy with leiomyoma as $p$ value was significant $(\mathrm{p}<0.05)$. Gloria et $\mathrm{al}^{9}$ also found higher incidences of LBW babies in pregnancy with leiomyoma in their study. Probable causes include higher incidence of preterm labor, IUGR, poor utero- placental blood supply and mechanical obstruction of fibroid to the growing fetus. 


\section{Conclusion}

Although most of the women have smooth course of pregnancy in spite of presence of leiomyoma, around $10-30 \%$ of them may develop pregnancy related complications and there is considerable increase in morbidity and mortality both to the mother and the baby. It is really surprising that most of the leiomyoma are accidentally diagnosed on routine ultrasonography in early pregnancy or during some non gynecological indications. 3D ultrasonography should be preferred to detect leiomyoma more precisely in pregnancy and also to avoid false positive results. While a major percentage of women do not face any adverse symptoms, there are cases where the size and location of fibroids can cause pregnancy related complications and should be rated as high risk pregnancy. Obstetricians should be prepared to manage severe PPH after vaginal births and caesarean deliveries in pregnancy with leiomyoma. Despite widespread occurrence, there is much research get to be done to fully understand the causes, prevention and treatment of leiomyoma. Moreover, a long term repeated ongoing studies are required to clarify the association between leiomyoma and adverse obstetric outcome to minimize complications among pregnant women with uterine leiomyoma.

\section{Bibliography}

1. Qidwai II, Caughey AB,Jacoby AF: Obstetric outcomes in women with sonographically identified uterine leiomyomata. Obstet Gynecol 107:376,2006.

2. Stout MJ, Odibo AO, Graseck AS, et al: Leiomyomas at routine second trimester ultrasound examination and adverse obstetric outcomes. Obstet Gynecol 116(5):1056, 2010.

3. Laughlin SK, Baird DD, Savitz DA et al: Prevalence of uterine leiomyomas in the first trimester of pregnancy: an ultrasound screening study. Obstet Gynecol 113(3):630,2009.
4. Neiger R, Sonek JD, Croom CS, et al: Pregnancy related changes in the size of uterine leiomyomas. J Reprod Med 51:671,2006.

5. Salvador E, Bienstock J, Blakemore KJ, et al: Leiomyomata uteri, genetic amniocentesis, and the risk of second trimester spontaneous abortion. Am J Obstet Gynecol 186:913,2002.

6. Klatsky PC, Tran ND, Caughey AB, et al: Fibroids and reproductive outcomes: a systemic literature review from conception to delivery. Am J Obstet Gynecol 198(4):357, 2008.

7. Shavell VI, Thakur M, Sawant A, et al: Adverse obstetric outcomes associated with sonographically identified large uterine fibroids. Fertil Steril 97(1):107, 2012.

8. Devis JL, Ray Mazumder S, Hobel CJ, Baley K, Saspo D. Uterine leiomyoma in pregnancy: a prospective study . Obstet Gynecol 1990; 75:41-4.

9. Gloria D, Coronado MS, Lynn M, Marshall SC et al: Complications in pregnancy, labor and delivery with uterine leiomyomas; Obstet Gynecol:95(5),76469, 2000.

10. Parazzini F, La Vecchia C, Negri E et al: Epidemiologic characteristics of women with uterine fibroids: A case control study. Obstet Gynecol, 1989;74:707-09.

11. Katz VL, Dotters DJ, Droejemeuller W. Complications of uterine leiomyomas in pregnancy. Obstet Gynecol. 1989;73:59396.

12. Vergani P, Ghidini A, Strobelt N, Roneaglia N, Locatelli A, Lapinski RH, MangioniC. Do uterine leiomyomas influence pregnancy outcome? Am J Perinatal1994; 11: 356-58.

13. G Iram Qidwai, Aaron B, Coughey and Alison F Jacoby. Obstetric outcomes in women with sonographically identified 
uterine leiomyomata: Obstet Gynecol 2006; 107:376-82.

14. Benson CV, Chow JS, Chang Lee W, Hill JA III, Doubilet PM. Outcome of pregnancies in women with uterine leiomyomas identified by sonography in its first trimester. J Clin Ultrasound 01 Jun 2001: 29 (5): 261-64.

15. Vollenhoven BJ, Lawrence AS, Healey DL 1990. Uterine fibroids: A clinical review Br J Obstet Gynecol; 97: 285-98.

16. Shailesh Kore, Anahita Panhole, Aparna Hegde, Sangeeta Kulkarni, Miti Ahuja, VR Ambiya. Pregnancy with fibroid. J Obstet Gynecol Ind 54(4):July/August 2004: 361-62.

17. Katz VL, Dotters DJ, Droegemeuller W. Complications of uterine leiomyomas in pregnancy. Obstet Gynecol 1989;73:59396. 